\title{
AVALIAÇÃO DO CONSUMO ALIMENTAR E USO DE SUPLEMENTOS DE PRATICANTES DE MUSCULAÇÃO
}

\author{
Anne Jeyssen De Sousa Araujo ${ }^{1}$ \\ Andreia Moura Nunes ${ }^{2}$ \\ Luiz Marly Freitas De Carvalho
}

Resumo: O presente estudo teve como objetivo avaliar o consumo alimentar e o uso de suplementos de indivíduos que praticam musculação. Foi realizado na zona sudeste de Teresina- Pl, composta por 50 indivíduos, de ambos os sexos. Realizou-se a avaliação nutricional através da obtenção do peso, altura, IMC, e o percentual de gordura. Aplicou-se um recordatório de 24 horas e foi aplicado um roteiro de entrevista para verificar os suplementos mais consumidos. Os dados coletados foram inseridos em banco de dados do programa SPSS para análise estatística dos resultados, e feitas aplicação de testes estatísticos. $34,78 \%$ eram do sexo feminino e $65,22 \%$ do sexo masculino. $74 \%$ foram classificados eutrófico segundo o IMC e $34 \%$ foram considerados ideais através do percentual de gordura. O suplemento com maior índice de consumo foi o whey protein, com uma porcentagem de 52,17\%. O grupo alimentar mais consumido pelos indivíduos estudados foi o grupo das carnes e o grupo das frutas.

Palavras-chave: Consumo alimentar; Obesidade; Suplementos; Musculação.

\footnotetext{
${ }^{1}$ Nutrição/Faculdade Santo Agostinho - FSA, Brasil. E-mail: nutri.annearaujo@gmail.com.

${ }^{2}$ Nutrição/Faculdade Santo Agostinho - FSA, Brasil. E-mail: andreiamnunesnutrition@gmail.com.

${ }^{3}$ Nutrição/Universidade Federal Do Piauí - UFPI, Brasil. E-mail: lumarnahid@gmail.com.
} 